\title{
Los rostros de la justicia: un planteamiento desde la arquitectónica pragmático- fenomenológica
}

\section{The faces of justice: an approach based on pragmatic-phenomenological architecture}

Aceptación: marzo 2008.

Jovino Pizzi ${ }^{1}$

Aprobación: julio 2008 .

\section{RESUMEN}

El giro ético introduce cambios a la concepción de la justicia. Las exigencias de aplicación señalan que, además del aspecto jurídico, hay que garantizar también su aplicabilidad a los diversos ámbitos: social, económico, cultural, entre otros. Sin embargo, el modelo que tenemos sigue los fundamentos liberales, como es el caso de la justicia distributiva de Brasil.

Palabras clave: Giro ético, justicia, el modus operandi liberal.

\begin{abstract}
The ethical turn introduces changes to the justice conception. The application exigencies point that, as well as juridical aspect, it is also necessary to guarantee its different aspects application, such as social, economic, cultural and others. The actual model that we have follows the liberal fundaments, as it happens in Brazilian distributive justice.
\end{abstract}

Key words: Ethical turn; Justice; the liberal modus operandi. 
1. El giro ético y la nueva configuración de la justicia

El ethical turn de la filosofía sigue dando vueltas y, con ello, los conceptos asumen diferentes orientaciones. La nueva configuración en la ética señala hacia las cuestiones de fundamentación y de aplicación. Eso significa que no hay más una ética general -como lo teníamos hasta los años 60-, lo que modifica no solamente la ética como tal sino también los diversos ámbitos de la vida práctica. Por un lado, se habla de un déficit ético, es decir, una pobreza en la propia ética y en su significativa estrechez en la aplicabilidad práctica; pero, por otro, nuevos frentes se abren, con to cual diferentes aspectos de la vida práctica encuentran formas de aplicar los principios y normas morales. En este proceso, nuevos conceptos nacen y otros son reemplazados, así como otros pasan por una revalorización. La justicia es uno de los conceptos que ha tenido una atención especial, con un abanico de concepciones, como justicia social, distributiva, económica, cultural o multicultural, etc.

Las exigencias de aplicabilidad señalan que la ética y la propia justicia no se resumen a conceptualizaciones. Y, por eso, la discusión apunta hacia la necesidad de ir más allá de la cuestión semántica y tratar de ver los aspectos pragmáticos de la justicia. La necesidad de modelos de aplicación exige saber como es posible una justicia distributiva en un modelo de sociedad liberal y señalar sus limitaciones. Al final, ese es uno de los modelos que se aplica en nuestras sociedades liberales. Sin embargo, eso no significa que es el único, pero no me parece sensato olvidarlo o rechazarlo por completo.

Con toda seguridad, los cambios de la filosofía y la insistencia en la aplicabilidad práctica de los discursos morales exigen una orientación normativa hacia un nuevo ordenamiento político y económico. El giro ético de la filosofía ha proporcionado cambios significativos, con lo cual nuevas frentes se van abriendo para la racionalidad ético-comunicativa, como la bioética, ética y medio ambiente, sin hablar de la ética relacionada con la economía, política, instituciones, etc. No hay duda de que el ethical turn, o sea, la mudanza ética, indica otra dirección para la filosofía y, al mismo tiempo, otra configuación al ámbito moral (Pizzi, 2006).

Como dice Alcira Bonilla, las éticas del siglo XX "abordaron sus objetos caracteristicos de un modo tal que poco incidieron en los asuntos prácticos que fueron apareciendo como consecuencia del desarrollo de las ciencias y de la tecnología o de la dinámica propia de la vida social" (2006, p. 78). En efecto, los cambios son profundos $y$, por eso, la era de la ciencia ha pasado a exigir una nueva configuración o-como dicen los ingleses- un "nuevo diseño" para la ética, con lo cual la fundamentación pasa a exigir también formas de aplicación. La racionalidad práctica ha pasado a preocuparse de los diferentes ámbitos de la vida práctica, como es el caso del medio ambiente, la economia, las empresas, el ámbito de la genética y la manipulación humana, entre otros. Esa preocupación se ha transformando en tema para la filosofía e incluso para los diferentes campos o ámbitos de la vida cotidiana y hasta la academia misma, involucrando a todos los sujetos presentes y futuros.

En el fondo, el giro aplicado de la filosofía procura superar el déficit de la propia ética. Esa preocupación ha promocionado una transformación en la filosofía y, en consecuencia, de la propia ética. El debate involucra no solamente la filosofía, como también las demás ciencias. Como señala Alcira Bonilla, en uno de sus artículos, "sin desdeñar las contribuciones a la ética teórica por parte de disciplinas como la psicología, la antropología, la historiografía, la sociología, la teología y el psicoanálisis, esta colaboración se centra en investigaciones sobre filosofía moral o ética filosófica" (2006, p. 80). Por otro lado, a este debate se suma también los biólogos, los geneticistas, ambientalistas, médicos, físicos, etc. Por eso, la diversidad de ámbitos de la vida práctica exige un estudio sistemático de los diferentes campos de aplicación, tanto en relación a la bioética, el medio ambiente, la limitación de los recursos naturales y la economía, el mundo de los negocios y las empresas, entre otros.

En este momento, la atención especial involucra también la justicia. No se trata so- 
lamente de definir justicia, sino también de estudiar sus posibilidades concretas de aplicación a la vida práctica. El interés tiene dos razones. En primer lugar, la preocupación con las áreas sociales, especialmente con las instituciones y personas que tienen la función de promoción social y en la lucha por mejores condiciones sociales de las personas. En este caso, se trataria también de estudiar cómo las empresas deben tener un comportamiento ético y de cómo los diferentes grupos de intereses pueden exigirles un compromiso social responsable y con la justicia. Una formación académica crítica es fundamental, pero cuando esos profesionales van a las empresas, por ejemplo, no pueden aplicar todo to que han aprendido. Muchas veces los trabajadores sociales son obligados a una sumisión al modelo liberal, o sea, la instrumentalización de las relaciones.

La segunda razón viene de la política pública brasileña que, en el momento actual, promociona una forma de distribución, por un lado, a través de becas a estudiantes universitarios pobres y negros, para que estudien en universidades privadas (más de $400 \mathrm{mil}$ ) y, por otro, garantiza una renta mensual a las familias pobres. Actualmente, según los datos del Gobierno, el número de familias pasa de los 12 millones. De todos modos, la discusión remite al tema de la justicia. La mirada señala hacia politicas afirmativas, a través de una justicia distributiva. Sin duda, esa forma de distribución sigue el modelo liberal. Caso hubiera otro modelo, ¿sería viable? ¿De qué forma planear otro modelo de distribución, cuando lo que tenemos es ese? ¿Cómo entender lo que pasa y cuáles son las reales posibilidades de hacer justicia distributiva?

Efectivamente, el liberalismo no es univoco. De hecho, parece que el liberalismo asume tantas versiones cuantos son sus teóricos. Además de hablar de justicia y de sus aspectos semánticos, la preocupación indica un paso más, es decir, un reto hacia el ámbito pragmático. Porque los problemas actuales no son solamente económicos, sino también sociales, ambientales y políticos. Tampoco son preocupaciones aisladas o de un país $u$ otro, pues se trata de un rompecabezas que involucra la humanidad y el planeta como tal. Por eso, este planteamiento supone aclarar el contenido y los procedimientos que indiquen las formas capaces de transformar este ideal en un estilo de vida. En este caso, el modelo liberal tiene su propuesta, es decir, señala hacia politicas distributivas.

Sin embargo, la distribución significa algo de justicia. Por consiguiente, el cambio exige diseñar también una "arquitectónica conceptual" de la justicia (Ricoeur, 1997, p. 14). Quizá una arquitectónica pragmáticafenomenológica sea más sensata, porque las exigencias de justicia involucran también los afectados que han sido, durante mucho tiempo, sistemáticamente injusticiados. En otras palabras, nos remite a generaciones pasadas que han sufrido la exclusión de lo mínimo necesario para vivir. De ahí que la pregunta "¿qué es justicia?" nos lleva a señalar no solamente su aspecto semántico, sino también al aspecto pragmático. Se trata pues de comprender no solo "¿qué es?" sino también a "¿a quién?" y "¿cómo?". Ese planteamiento nos lleva a la fenomenología de la justicia, en donde la pregunta por "¿qué es justicia?" se encuentra confrontada con su aplicación práctica. Por lo tanto, las exigencias de justicia deben responder quiénes son los sujetos de la justicia, de modo que la búsqueda por definiciones remite a las posibilidades de aplicación.

En los últimos años, diversos autores han trabajado el tema. Rawls ha intentado presentar un modelo desde una configuración liberal. Otfried Höffe, Jürgen Habermas y Paul Ricoeur también participan de la discusión. En este sentido, la retomada no ocurre solamente ante el giro ético, sino también porque las motivaciones también han cambiado. Gran parte del pensamiento moderno ha abandonado el vínculo entre justicia, economía y la política. Es decir, la preocupación de la Edad Media se centraba en el vínculo entre paz y justicia (Gauvard, 2006, II, p. 55). En el siglo XX, la idea vuelve y Rawls ha sido uno de los autores importantes, así como otros. Macpherson (1991) habla de la ascensión y de la justicia económica. Para Habermas "la solidaridad es el envés de la justicia" (1999, p. 42). En efecto, la discusión indica hacia dos caminos. Uno de ellos trata de aclarar las discusiones entre autores; y otro intenta señalar la aplicabilidad de justicia. Y creo que este 
último aspecto es más interesante, con lo cual no significa abandonar el diálogo con los distintos pensadores.

\section{Un giro pragmático a la justicia}

Para comprender la arquitectónica pragmático-fenomenológica de la justicia, volvemos a Kant, cuando dice que algo puede ser "correcto en teoría, pero no sirve para la práctica" (2000, p. 3). En efecto, el tránsito entre la teoría y la práctica lleva a Kant a postular por una racionalidad que sea teórica y práctica. El ámbito moral se vincula a la última, con lo cual la justicia presenta también una vinculación al aspecto práctico, es decir, con la vida y el convivir. No se trata por tanto de condiciones empíricas, ni tampoco de ofrecer un abanico de concepciones o definiciones.

Por eso, las exigencias prácticas subrayan una "práctica calculada en el orden del resultado" (Kant, 2000, p. 6), lo que supone una posibilidad de transformar las exigencias de justicia en una forma distributiva de los bienes, incluso los materiales. El binomio justicia y paz, tan importante para algunas comunidades del medievo, ahora cambia y se transforma en justicia y solidaridad, con lo cual no se resume a la resolución de conflictos, sino a políticas de distribución de los bienes. La ampliación significa no simplemente una relación privada o entre familias, o el hecho de dar a cada uno lo que le es debido, sino un deber moral, pues se trata de un compromiso entre todos.

De ahí que la cuestión no se resume a definir lo que es justicia (aspecto semántico), pues hay que estudiar además "¿a quién?" y "¿cómo?", es decir, pasar al aspecto pragmático, con lo cual llegamos al nivel postconvencional de justicia. Ese movimiento lo denominamos la necesidad de vivir la experiencia de la justicia, lo que significa, en otras palabras, la necesidad de confrontarse con su aplicación. Es decir, la pregunta "¿qué es justicia?" remite a las posibilidades de su aplicación práctica.

Gran parte de la sociedad medieval, principalmente la francesa, toleraba la venganza como medio para la resolución de con- flictos, de modo especial cuando se trataba de crímenes contra la honradez (Gauvard, 2006 II, p. 56). Se trataba de una solución priva$\mathrm{da}$, a veces con la intermediación de un juez o árbitro. Este era uno de los caminos para la resolución de conflictos. Sin embargo, la justicia no se limita al campo privado, mientras presenta un carácter público. Ahi nace una distinción importante: la justicia pública y la oficial. Con eso, tenemos la justicia legal, regulada por un poder judiciario, encargada primordialmente de regular los conflictos particulares, garantizando los derechos a cada individuo.

En este sentido, hablar de justicia significa también identificar los orígenes del derecho oficial de las sociedades occidentales. Simón y Barrio afirman que la explicación del modelo common law ha sido dada por Victoria Iturralde. Ese modelo presenta ocho características:

1. El common law es un conjunto de principios y prácticas no escritas cuya autoridad no deriva de una declaración de mandato singular y positivo a través de una explicita fuente de origen legislativo o ejecutivo; 2 . Es un derecho formado por los jueces (judge-made-law); 3. Los tribunales inferiores están obligados a seguir las decisiones (precedentes) de los Tribunales jerárquicamente superiores; 4. Los principios del common law, provenientes de la antigua costumbre, solo pueden ser autorizadamente conocidos (o descubiertos) y aplicados (declarados) en el contexto de los procedimiento judiciales; 5. El common law es preponderantemente práctico, no teórico. En su centro está el adversary proceeding en los Tribunales (una confrontación entre dos partes contendientes, cada una haciendo alegaciones y peticiones en el contexto específico de la controversia); 6 . Es un derecho no escrito, en el sentido de que no está codificado; 7. Las reglas del derecho del common law (menos abstractas que las del civil law) son reglas que tratan de dar la solución a un proceso, y no reglas generales para el futuro. Al mismo tiempo los principios juridicos, tal y como son desarrollados por los Tribunales, se someten a una serie limitada de reglas emanadas 
de decisiones anteriores; 8 . Las reglas acerca de la administración de la justicia, del procedimiento, de la prueba, asi como las relativas a la ejecución de las decisiones judiciales tienen un interés igual, $e$ incluso superior, a las reglas relativas al fondo del derecho (Simón y Barrio, 2004, pp. 17-18).

Como se puede percibir, existe una fuerte tradición vinculada a la common law, con aspectos muy distintos de la civil law. En efecto, no existe un sistema puro, porque se puede identificar diferencias sustantivas, no solamente en el origen y su influencia en los distintos países, sino también en relación a los principios, procedimientos e instituciones jurídicas (Simón y Barrio, 2004, p. 17). Para estos autores, un ejemplo típico está en la teoria del Parens Patriae (de 1324), cuando ha sido promulgada la De Prerogativa Regis, que trataba de organizar los derechos y deberes de los reyes ingleses de la época feudal (2004, p. 21).

Actualmente, el mundo occidental tiene presente dos tradiciones juridicas diferentes. El sistema anglo americano del common law cuyos orígenes están en el medievo. Ese modelo es adoptado, hoy día, por el Reino Unido (menos Escocia, que posee un sistema mezclado), Irlanda, la mayor parte de los Estados Unidos, Canadá (excepto Quebec, que tiene un sistema mixto), Australia, Nueva Zelanda, India, República de Sudáfrica y, en general, casi todos los países pertenecientes a la Comonwealth. Por otro lado, la tradición caracterizada por la civil law sigue el modelo del derecho romano-germánico, con sus modificaciones posteriores, especialmente las napoleónicas. Se trata de una tradición europea, o sea, típicamente continental, presente en el derecho español, francés, alemán o el italiano, entre otros (Simón y Barrio, 2004, p. 17).

Por eso, la cuestión de la justicia señala hacia el génesis del derecho y de su legitimación, cuyas vertientes jurídicas y legales presentan dos orígenes distintas, aunque se mezclen en algunos aspectos. La Constitución americana, de 1787 , es uno de los ejemplos más significativo del civil law, ajena al common law, mientras las decisiones dependen exclusivamente de la constitucional law (Simón e Barrio, 2004, p. 18), es decir, las decisiones están vinculadas a la Suprema Corte, tiene poderes definitivos.

Así, pues, las posibilidades de legitimación de las normas jurídicas se enfrentan con un conjunto de variables o especificidades, que pueden ser observadas en sus diferentes configuraciones del sistema politico, o sea, del orden constitucional. Evidentemente, la mayor parte de los países latino americanos sufren la influencia europea, con lo cual limita la cuestión de la justicia al derecho juridico, de forma que el Estado sea el que garantice y administre la justicia.

Las tratativas de otras formas de justicia casi no prosperan. El problema se agudiza cuanto el modelo sigue las reglas del liberalismo. Las expectativas no se limitan a la justicia privada, sino a la cuestión pública y, por tanto, la demanda social por justicia, lo que conlleva no solamente la resolución de conflictos entre personas, familias o grupos, sino también por justicia social, económica y cultural o intercultural. No deseamos aquí diseñar cada uno de estos rostros de la justicia, sino indicar que sus exigencias no se limitan a las definiciones (aspecto semántico). Más allá de eso, la justicia presenta un carácter pragmático-fenomenológico, lo que signifi$\mathrm{ca}$, en otras palabras, la necesidad de aplicación práctica y, además, una aplicabilidad que pueda contemplar los diferentes aspectos (jurídico, social, económico y cultural o intercultural).

El discurso liberal propone un Estado recaudador y el traspaso a la sociedad a través de las ayudas sociales. Sin embargo, en el libro Capitalismo contra capitalismo (1993), Michel Albert señala los diferentes momentos y papeles que el Estado ha asumido dentro del capitalismo: unas veces más intervencionista, otras $\sin$ grandes intervenciones que osbtaculicen la dinámica de la actividad de los individuos. De todas formas, para los neoliberales, el Estado no está completamente ausente en sí, sino más bien "lo que desaparece es el principio de soberanía y el poder de coerción que deriva de él" (Souza Santos 2007, p. 37). El Estado sigue siendo el socio legítimo del sistema capitalista y de la gobernabilidad 
misma, pero siempre dentro de los límites del sistema, o sea, en su capacidad "no estatal" mientras trate de asegurar la realización de las libertades individuales de todos, exaltando por tanto al emprendedor. Esa versión del capitalismo subraya que el enriquecimiento de cada uno, sin esperar del Estado ayudas, porque esos "programas sociales" siempre son una coartada de la pereza. "¡Que los pobres se pongan a trabajar, en lugar de esperar del Estado todas esas ayudas! En cuanto a las necesidades elementales de los más desprotegidos y de los marginados, la caridad ya se ocupará de ellos. Ese no es asunto del Estado" (Albert, 1993, p. 34).

\section{La justicia o el modus operandi liberal}

La cuestión central de hoy día remite al modelo de democracia y de una economía capitalista liberales. Se trata de un modus operandi presente en nuestras sociedades. Por eso, el aspecto pragmático-fenomenológico de la justicia nos lleva a preguntar no solamente por sus orígenes y sus procedimientos, sino más bien por las víctimas del pasado y del presente. El liberalismo pretende coordinar la acción a partir de compromisos entre intereses privados. Se trata de asegurar los bienes de cada individuo y garantizar a cualquier sujeto las condiciones de tales bienes. El Estado (la administración pública) debe resguardar los medios para la realización de los intereses particulares. En este caso ser ciudadano significa tener derechos asegurados, a través de los cuales puede negociar y garantizar sus propios intereses ante los demás y al Estado.

Ese razonamiento indica que no llegamos a Rousseau o a los ideales ilustrados. Cuando estoy haciendo hincapié en América Latina, no quiero olvidarme de Europa, pero señalar lo que hemos experimentado en nuestros paises. No hemos tenido pacto social, sino pacto de élites. Aunque sea posible comprender que los derechos políticos sean respetados, en lo económico estamos lejos de alcanzar un mínimo razonable a los ciudadanos de las repúblicas. Entonces, la justicia significa igualdad jurídica, pero también igualdad social y económica, lo cual nos exige condiciones formales y materiales para su efectividad.
Ese planteamiento nos lleva a insistir que la justicia pase de lo semántico al aspecto pragmático. En este sentido, la pregunta "¿a quién?" nos lleva a las víctimas de la injusticia. Ese grito de indignación o de perplejidad -como dice Javier Muguerza (1990)- se convierte en un llamamiento que nadie puede recusar, porque se trata de llamamiento, una convocatoria que nadie puede rechazar y tampoco abandonarla.

Entonces, si no hay más remedio, porque no podemos negar esa convocación, tenemos que partir por el "¿cómo?" podemos luchar por la justicia y "¿cómo?", de hecho, los injusticiados pueden reparar sus dolores. Porque el grito y la indignación precede las teorías y ya está presente en la infancia o incluso precede el momento prenatal de algunas generaciones. Efectivamente, la traición de los ideales de igualdad afecta a muchos, porque el reparto no ocurre. Eso genera, por un lado, una especie de violencia, dolor y sufrimiento $y$, por otro, un gozo, fruición y un placer entre aquellos que disfrutan de los bienes. Dolor por parte de aquellos que pasan por necesidades y que están debajo de lo aceptable; y gozo por parte de aquellos que lo tienen todo.

Por eso, la igualdad presupone también igualdad socioeconómica, sin la cual no hay formas de pensar sobre la justicia. Si el sujeto es consumidor, que sea también consumidor de derechos económicos. Quizá sea una forma de rescatar la otra cara de la razón (Muguerza, 1990, p. 628). 0, entonces, la otra cara de la justicia. El "¿cómo?" supone, por tanto, una forma de distribución de la riqueza o de los recursos escasos. Por eso, el punto clave está en insistir por una justicia también económica.

Nuestra perspectiva apunta hacia la disminución de la pobreza a través de un instrumento intrínseco al modelo liberal, es decir, desde dentro. Se trata de fortalecer lazos de solidaridad y de justicia. Los dos aspectos exigen, por un lado, un compromiso moral entre las gentes $y$, por otro, una justicia política. Como se puede ver en el Cuadro 1 , el modus operandi del modelo liberal señala que el Estado asume un estatus de mediación, con lo cual se haría cargo de establecer limi- 
tes a la libertad a los individuos (A). En este caso, tendria que limitar las ganancias (B) y distribuirlas a los que están por debajo de lo aceptable (C).

El aspecto "d" significa un límite aceptable, es decir, una delimitación de los bienes entre B y C. La limitación en B significa que arriba no es admisible, porque ultrapasa la línea de la justicia, un grado máximo incluso para las ganancias. Por debajo de $\mathrm{C}$ estaría el nivel no aceptable a ningún ser humano.

Por eso, la justicia supone solidaridad, pues las gentes admiten que los que ganan más repasen, a través del Estado, a los que aún están debajo de C. La justicia distributiva supone, pues, ese compromiso en buscar una sociedad libre de la dominación de los más ricos sobre los demás.

Macpherson dice que el modelo de Rawls "satisface los criterios para una teoría de la justicia económica, mientras propone realmente someter los acuerdos distributivos a un principio ético" (1991, p. 26). Para este autor, el problema está en la forma compe- titiva del modelo liberal, es decir, "una economía totalmente dominada por el mercado donde la reacción negativa de los empresarios al incremento de los impuestos hace con que disminuya la productividad global (1991, p. 26). Al final, el mercado acaba dominando las relaciones, con lo cual las exigencias normativas pierden fuerzas, es decir, la ética no puede hacer valer sus principios. Ante el escenario actual, es necesario entender que la diversidad de los mundos de la vida nos sitúa ante diferentes cosmovisiones e interpretaciones, diversas interculturalidades y formas de vivirlas, o sea, una pluralidad multiforme y polifónica. De ahi entonces la importancia de una perspectiva ética para crear convivencia ciudadana, ya que ella trata del lugar habitual, o sea, del lugar donde vivimos. Esta definición pone en relieve la necesidad de ir creando hábitos y costumbres que orientan la acción, tanto en relación al ámbito local, nacional o cosmopolita. Por tanto, la ciudadanía debe ser entendida a partir de tres combinaciones: a) la pertenencia a un Estado constitucional; b) esos enlaces con otras comunidades políticas; y, por último, c) reconociendo los vínculos locales y el contexto cultural. La

Cuadro 1. Los cánones de la justicia distributiva

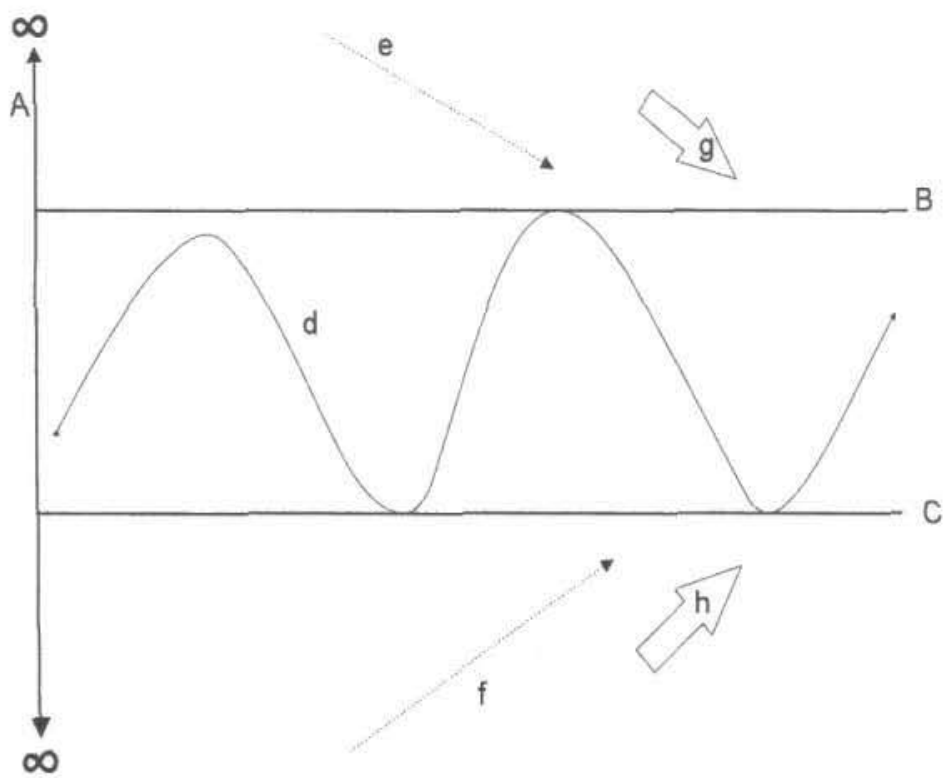




\section{Revista CUHSO volumen $16 \mathrm{~N}^{\circ} 2$}

simetría entre esas tres esferas exige un tratamiento igual entre ellas mismas.

\section{Referencias}

ALBERT, Michel. Capitalismo contra capitalismo. Buenos Aires; Barcelona; México: Paidós, 1993.

BONILLA, Alcira. "¿Quién es el Sujeto de la Bioética? Reflexiones sobre la vulnerabilidad". In: LOSOVIZ, Alicia I.; VIDAL, Daniel A. \& BONILLA, A. Bioética y Salud Mental. Intersecciones y dilemas. Buenos Aires: Akadia, 2006.

GAUVARD, Claude. "Justiça e paz". In: LE GOFF, J. \& SCHMITT, J.-C. Dicionário temático do ocidente medieval. São Paulo: EDUSC, 2006, dos volúmenes.

HABERMAS, J. La inclusión del otro. Estudios de teoría política. Barcelona; Buenos Aires; México: Paidós, 1999.

HÖFFE, Otfried. Justicia politica. Barcelona; Buenos Aires; México: Paidós, 2003.

KANT, I. Teoria y práctica. 3ra ed., Madrid: Tecnos, 2000.
LOSOVIZ, Alicia I.; VIDAL, Daniel A.; BONILLA, Alcira. Bioética y Salud Mental. Intersecciones y dilemas. Buenos Aires: Akadia, 2006, pp. 77-88.

MUGUERZA, Javier. Desde la perplejidad. México: Fondo de Cultura Econômica, 1990.

PIZZI, Jovino. Ética e éticas aplicadas. A reconfiguração do âmbito moral. Porto Alegre: EDIPUCRS, 2006.

RICOEUR, Paul. O justo ou a essência da justiça. Lisboa: Instituto Piaget, 1997.

RICOEUR, Paul. A memória, a história, o esquecimento. Campinas: Editora Unicamp, 2007.

SIMÓN, Pablo y BARRIO, Inés M. ¿Quién decidirá por mí? Madrid: Triacastela, 2004.

SOUSA SANTOS, B. "Más allá de la gobernanza neoliberal: el Foro Social Mundial como legalidad y política cosmopolitas subalternas". In: SOUSA SANTOS, B. y RODRÍGUEZ GARAVITO, El derecho y la globalización desde abajo. Barcelona: Anthropos; México: UAM-Cuajimalpa, 2007, pp. 31-60. 